\title{
PEDAGOGIAS EM DISPUTA: DENIZE SEPULVEDA ENTREVISTA SARA WAGNER YORK
}

DISPUTING THE PEDAGOGIES: DENIZE SEPULVEDA INTERVIEW SARA WAGNER YORK

\author{
(D) https://orcid.org/0000-0002-4397-891X Sara Wagner York ${ }^{\mathrm{A}}$ \\ (D) https://orcid.org/0000-0001-9049-5200 Denize Sepulveda ${ }^{\text {B }}$ \\ ${ }^{\text {A }}$ Universidade do Estado do Rio de Janeiro (Uerj), São Gonçalo, RJ, Brasil \\ ${ }^{\text {B }}$ Universidade do Estado do Rio de Janeiro (Uerj), São Gonçalo, RJ, Brasil \\ Recebido em: 30 abr. 2021 | Aceito em: 6 jul. 2021 \\ Correspondência: Sara Wagner York (sarawagneryork@gmail.com)
}

\section{Resumo}

O apresente texto desdobra formas de se fazer e falar sobre e com sujeitas implicadas com suas salas de aula e, sobretudo, com o ensino de formação de professoras e professores, mas não só, é sobre formas (in)visíveis de Educação. Ao trazermos essa entrevista, podemos de algum modo produzir nossos arquivos e até as nossas memórias que estão em constante disputa. Em 2018, a professora Sara Wagner York, afirmou em muitas de suas lives ter catalogado mais de 500 Trabalhos de Conclusão de Curso de Pedagogia, do curso de Educação a Distância - EAD da UERJ entre os anos de 2010 a 2017. Após levantamento inicial verificou se que as palavras Ludicidade, Letramento e Diversidade eram as mais presentes. Diante do levante conservador a partir do Golpe de Estado de 2016, ficou ainda mais perceptível a inserção de mulheres e homens evangélicos nos cursos de docência e principalmente nos cursos de Pedagogia. Evangélicas/os inseriam "diversidade" como palavra-chave, intencionando uma educação para todos. Um movimento similar também era produzido por jovens e adultas/os/es trans e travestis que perceberam a educação, e principalmente a Pedagogia, como instrumento fundante para mudança no cenário nacional. Esta entrevista realizada no ano pandêmico de 2021, no mês de setembro, marca um movimento cada vez mais frequente: a ocupação da diferença (marcada pelo gênero, sexualidades e identidades - e seus vários corpos) na cena educacional brasileira.

Palavras-chave: travesti da/na educação; pedagogia em disputa; movimentos sociais; transepistemologia; formação de professoras/es.

\begin{abstract}
The present text unfolds ways of doing and talking about and with subjects involved with their classrooms and, above all, with the education of teachers, but not only, it is about (in)visible forms of Education. By bringing this interview, we can somehow produce our archives and even our memories that are in permanent dispute. In 2018, Professor Sara Wagner York stated in many of her lives that she had catalogued more than 500 monographs from the Pedagogy Course, Distance Education - EAD of the University of the State of Rio de Janeiro - UERJ between the years 2010 and 2017. After initial survey it was verified that the words Ludicity, Literacy and Diversity were the most present. Faced with the conservative uprising from the coup d'Etat of 2016, the insertion of evangelical men and women in teaching courses and especially in Pedagogy courses became even more noticeable. Evangelical women and men inserted "diversity" as a key-word, intending an education for all. A similar movement was also produced by trans and travesti youths and adults who perceived education, and especially Pedagogy, as a fundamental instrument for change in the national scenario. This interview held in the pandemic year of 2021, in the month of
\end{abstract}


September, marks an increasingly frequent movement: the occupation of difference (marked by gender, sexualities and identities - and their various bodies) in the Brazilian educational scene.

Keywords: travesti in/of education; disputed pedagogy; social movements; transepistemology; teacher training.

\title{
Abrindo a caixa de pandora
}

\author{
Autoetnografia e teoria queer compartilham \\ afinidades conceituais e intencionais: ambas recusam \\ noções recebidas de metodologias ortodoxas e se \\ concentram na fluidez, intersubjetividade e \\ capacidade de resposta às particularidades (...) \\ ambos se recusam a encerrar a inventividade, \\ recusam a legitimidade estática \\ Foucault 1981, Gingrich-Philbrook 2005
}

1 - Sara você é uma mulher, travesti, pai, avó, acadêmica, da/na educação, militante da causa trans e pela vida. Quem te olha percebe uma mulher forte que luta pelos direitos das pessoas trans, mas sei que nem sempre foi assim. Conte um pouco da sua trajetória de vida.

Deficiente visual! Segundo a "Convenção Internacional sobre os Direitos das Pessoas com Deficiência" (CIDPD; Decreto $N^{0}$ 6.949/09) as pessoas com deficiência são aquelas que têm impedimentos de longo prazo de natureza física, mental, intelectual ou sensorial, os quais, em interação com diversas barreiras, podem obstruir sua participação plena e efetiva na sociedade em igualdades de condições com as demais pessoas (Art. $1^{\circ}$, BRASIL, 1988). Sou monocular desde tenra idade em razão de um glaucoma impulsionado por uma sífilis congênita. Fui operada tardiamente do glaucoma com pouco mais de 6 meses de vida. O médico naquela época, era considerado uma referência no Brasil, lembro-me apenas do seu primeiro nome, Ruberpaulo. Estar naquele consultório e sob tratamento médico "de excelência" ajuda-me a informar o leitor sobre a família branca e de classe média que fiz parte em pouco mais de uma década de vida. Falar sobre as múltiplas condições de ser e acessar o mundo por um corpo (d)eficiente e (in)capaz, talvez seja um bom início para esta conversa. Eu acho interessante o modo linear como você apresenta a pergunta, assim, eu gostaria de inicialmente dizer do meu contentamento, enquanto acadêmica, pesquisadora e professora à dialogar sobre as condições que possibilitam a participação de uma vida como a minha, caminhando pelo cenário Educacional (trans)nacional. Falo do modo linear porque enquanto mulher - e essa compreensão me chega muito cedo, assim como a deficiência visual - com monocularidade vou me dando 
conta de outras sobreposições e camadas a partir delas. A travestilidade não precede minha mulheridade, mas justifica minha tentativa de inserção no mundo do poder cis-falo-centrado e da (dis)secção do mach(ad)o (em alusão ao texto de Alexsandro Rodrigues, apresentado no II Seminário Gênero, Sexualidades e Educação na ordem do dia - Interseccionalidades em (Re)Existências). Compreender-me como travesti chega um pouco mais adiante, por volta dos 12 anos de idade, ao perceber que muito dos efeitos da minha existência, eram percebidos como não adequados à sociedade. Querer sentar de pernas cruzadas, andar e falar (como mulher). Era interessante atender ao telefone, naquela época fixo, e as pessoas me perguntarem, "gostaria de falar com fulano, você é filha dele?". Naquele momento a cisgeneridade, enquanto força governamental ainda não sendo nomeada, a heterossexualidade normativa compulsória, e sobretudo presumida, eram pautas de pouquíssimos estudos no Brasil, mas o corpo trans já era latente. Talvez um dos primeiros textos, nos chegue pelos estudos da mulher, com os trabalhos das sociólogas Heleieth Saffioti (1978; 1979; 1981) e Eva Altermann Blay (1978), mas a então comunidade GLS - de gays, lésbicas e simpatizantes - popularizava um outro movimento, mais "gay" e americanista. Em Goiânia - GO, minha cidade natal, as bichas lindas e bem vestidas já eram referência, assim como o modo excludente como as afeminadas e eu éramos vistas. Não me lembro de muita coisa, mas havia muitos militantes que já falavam sobre alguns ativistas que eu pouco lia, mas muito sabia, em razão da então epidemia da AIDS/HIV; hoje sabemos que se trata de uma pandemia. Eu acreditava que iria passar, inclusive a dor de tantas perdas. A minha adolescência é marcada por esse momento. Tínhamos grupos propagan(dean)do o uso da "camisinha" e muita gente jovem morrendo, muitos amigos e amigas, gays e travestis, sucumbindo à falta de Estado e à repressão promovida pelos apoiadores da Ditadura Militar. O patriarcado assim se estabelece na minha vida por uma trajetória na Igreja Católica Apostólica Romana, com o catecismo, primeira comunhão e crisma, entre meus 9 e 14 anos; momento em que tive minhas primeiras experiências sexuais com alguns tios, primos e padres. Fui iniciada logo na sequência nas religiões de matrizes africanas (na Umbanda do Centro Espírita da Mãe Rosa e no Terreiro da Nação de Ketu do Pai João de Abuque). Fui informada, entre um sabão e uma passada de mão, por um coleguinha de "pega-pega" que iria para o inferno da religião dele que, aliás, segundo ele, era a única que poderia me salvar do ato gostoso que acabávamos de cometer. Carregada de culpa, o medo do inferno e ausência de um deus que me amasse, mas que me puniria por sucumbir ao desejo, as igrejas neopentecostais de vertente fundamentalistas, a "Assembleia de Deus" e a Igreja "Deus é Amor", chegam trazendo outras transas, amores e o filho. Foi neste momento que conheci a futura mãe do meu filho, gerado em um único encontro. 
Conheço as nuances acadêmicas no curso de Enfermagem, não finalizado, e a possibilidade profissional do trabalho com dança, a partir do balé clássico e do jazz, mas também da atuação e da experimentação nas montagens coreográficas nos musicais de teatro produzidos por mim, naquele momento, enquanto coreógrafa. Acho importante mencionar estes dados que, enquanto cotidianistas, o caráter (in)formativo faça-se evidente nos/com os vários espaços-tempos que produzem algum sentido para mim hoje. Muitos dos espetáculos que datam de 1989 a 1996 não possuem o meu nome artístico ou cível, em razão de determinações que naquele momento compreendia como adequações comerciais, mas que hoje percebo como transfobia. A filiação do meu nome às produções cênicas, sobretudo produzidas para um público cisgênero, supostamente heteronormativo e, sobretudo, infantil naquele momento, como formas dissociadas. "Meninas e meninos seriam isso e você é outra coisa, mas não para produzir". Tenho a vida marcada por vários momentos de dor, mas três deles são cruciais: a expulsão de casa em razão da travestilidade; a retirada do meu filho do meu convívio em razão da travestilidade; e a perda de formação universitária, espaços de convivência e possibilidades trabalhistas em razão da travestilidade. A condição de observar reiteradamente pessoas cisgêneras como corpos privados, pessoas LGB como corpos públicos e Intersexo, trans e travestis como corpos púbicos. Nada além de um púbis desmembrado, as peças do corpo-bicho à venda no açougue, genital-generificado, anatomopérfido. Um conjunto de fatores foram necessários para que eu desistisse, inicialmente, de lutar e, posteriormente, de viver naquele momento, e por esse motivo muitos desencontros se tornam absolutamente centrais para a condição de usuária de drogas ilícitas e de pessoa em situação de rua; o auto-abandono que combina processos de exclusão com processos de auto-exclusão. Assim, palavras como misoginia, transfobia, patriarcado, coexistem em muitas vidas trans e de travestis de formas reiteradas, desde que me compreendo como sujeita no mundo e desde o final da infância. Hannah Arendt (2011, p. 262) diz que "sabemos da existência de povos sem mundo", e talvez, enquanto moradora de rua, eu tenha experienciado algumas dores: ser uma pessoa com uma família muito grande, e toda esta família em processo reiterado de rejeição, repulsa e abandono, a minha adolescência de travesti-imigrante (YORK, 2020). Falamos atualmente em ancestralidade, impulsionadas pelas escritas pretas, e talvez essa seja uma palavra também muito profunda, quanto densa, em minha jornada. Quando penso nas minhas raízes sou alocada em um lugar de não lugar: eu não conheço a minha genitora, eu não conheço o meu genitor, apenas a pessoa que me retirou a possibilidade de uma outra vida, em um hospital e me entregou para uma sogra que sequer conhecia, minha avó paterna, a mãe do homem que conheci como 
pai, o homem que caiu no "golpe da barriga". Apaixonada pelo amante, a mulher que cresci chamando de mãe, já era mãe de 4 filhos de um marido 20 anos mais velho, quando decidiu fugir com o amante, pois estava supostamente grávida - e como de família cristã, não convinha abortar -, mas para que o plano desse certo precisava de uma criança, e como ela não podia engravidar, sendo financeiramente bem-sucedida e com cumplicidade médica apoderou-se do recém-nascido. Em alguns momentos da minha infância lembro-me dela dizendo que deveria ter me deixado onde me encontrou: com a doida da cidade que havia sido abusada por um artista de circo que por lá passava. Assim, o patriarcado, a misoginia, e a hierarquização dos gêneros e dos sexos antecedem a minha chegada ao mundo, e com ela a reiteração de expectativas e desejos que mal condiziam com a estruturação de uma família nos moldes previstos, cujos erros e defeitos fomentariam a própria idealização dessas práticas normatizadoras que a todo momento reitera o que devemos ser, para o que devemos mostrar e como devemos agir diante da produção ininterrupta de um CIStema. A dor da ausência, das perdas, das retiradas e da exclusão eram tão intensas que dizer "eu comi merda" para estar aqui, a mim não é alegórico, é literal. A travesti da/na educação (CARA, 2020) chega dessa forma através das leituras dos cotidianos quando explora a ação em um território, mas também com o território e daquele território. Isto é, o meu fazer docente dialoga com a exclusão que precede minha voz, estranha para aquele espaço.

2 - Nos conte um pouco sobre suas experiências na escola enquanto criança e adolescente? A escola foi uma agente de inclusão social para você? Qual a análise que você faz desse processo?

Um dos meus parceiros de escrita, Diego Lanza (dos Santos), fez um levantamento, em sua dissertação de mestrado, que aponta a maciça expulsão de jovens trans e travestis do ensino formal, a partir de narrativas com/juntas de meninas da Rocinha, no município do Rio de Janeiro. Luma Andrade apontava anteriormente tais ações como evasão sistêmica; Marina Reidel, na "Pedagogia do Salto Alto", apresenta formas resistentes de inserção docente; Megg Rayara, no "Diabo em forma de gente" diz, inclusive, que não tinha "espelhos" na infância e adolescência na/para construção da autoimagem. Todas resistiram e suas trajetórias mostram que a escola não inclui ou exclui, quem inclui são alguns professores/as e eles sempre existiram em todos os processos educacionais. Eu tenho duas experiências muito diferentes no ensino fundamental; enquanto aluna, a primeira parte do processo ensino-aprendizagem numa escola privada, que configurava todos os processos de estigma e discriminação baseados nessa 
estrutura discriminatória e prevista nas regulações e na própria legislação que, naquele momento, não discutia a existência de pessoas trans e pessoas travestis; e a segunda, na escola pública, onde a grandeza individual se propagava no respeito e/ou constrangimento de alguns professores que, naquele momento, também não sabiam lidar com as nossas questões. Estar em uma escola privada indicava as condições econômicas que meu pai e minha avó tinham de investimento sobre o ideal pretendido. Como disse, eu desconheço a procedência de minha própria história, a minha ancestralidade. Eu conheço alguns picados desta história e é a imersão numa farsa televisiva, que beira o fictício e o surreal, desde muito cedo que me desperta tanto a curiosidade sobre as formas de dominação que forja famílias convencionais, segredos familiares (como na maioria dos casos de pessoas Intersexo), sempre atendendo às demandas do cis-hetero-patriarcado. Deste modo, falar sobre estigma, violência e discriminação baseada em identidade de gênero, está muito relacionado às violências físicas, simbólicas, emocionais, verbais e, também, as sexuais, a rejeição e agressão por parte de - senão um, muitos - membros desta família de modo muito recorrente. Nos processos educacionais, portanto, em alguns momentos, eu passo por violações absurdas e indescritíveis na escola, não podendo reportá-las em casa onde as práticas discriminatórias reiteravam a violência. Os níveis de exaustão diante das agressões em ambos espaços hoje são evidenciados nos níveis de ansiedade, marcas pelo corpo e lembranças que provocam extremo mal-estar. Mesmo as autoridades no campo escolar, no sistema jurídico ou corpo policial ainda negam ajuda em vários Brasis, quando falamos de infâncias e adolescências dissidentes e/ou trans. A exclusão de pessoas não aderidas ao padrão cisheteronormativo por parte de membros da comunidade LGBTI+, naquele momento chamada GLS, também era muito grande. Pouco mudou, mas já é possível observar outros corpos desenhando novas potências e experienciando outras possibilidades. Em 2020, temos a incrível marca de 2.184 pedidos de uso de nomes sociais nos registros do ENEM, o que não significa exatamente 2.184 pessoas trans e/ou travestis, mas pessoas que estão usando uma forma de se sentirem melhor em uma forma de nomeação de si. A adolescência de todo jovem é marcada pelas mudanças e todos sabemos que é um momento crítico e, por vezes, desafiador para todos e todas ao nosso redor, mas quando mencionamos o corpo trans, tanto no âmbito familiar, educacional ou social ele é marcado pela baixa autoestima, por conta de práticas transfóbicas legitimadas nestes espaços. Um estudante que agride um colega é um agressor, um estudante que faz piada com pretos, é racista, do mesmo modo com as transfobias, mas por estarem sob júdice de um sistema cisgênero e branco, tais atos ainda são descritos como bullying em vários momentos no contexto escolar. Eu não estou dizendo que precisamos criminalizar e punir 
diuturnamente estudantes, mas que precisamos, com máxima urgência, abrir um diálogo saudável sobre esse terreno ainda inexplorado que envolve do estigma e discriminação à geração de tantas violências. $\mathrm{O}$ que eu tento dizer com tantos exemplos de dor vívidos na memória, é que essa situação está acontecendo agora em muitos lugares. Há a ausência da família por creditar à escola este trabalho; da direção escolar quando aloca as cenas de violência como fora dos muros escolares; e da sociedade quando acredita que "quem pariu, que embale" e com isso, mais uma vez, mulheres são colocadas como as grandes vilãs. Mas voltando à questão sobre o meu processo de inclusão social na escola, eu acho que na escola alguns agentes me incluíram socialmente e eu acabei por incluir a escola como espaço possível num processo de sobrevivência à violência sofrida cotidianamente em âmbito familiar. Se é possível fazer uma análise, eu retorno ao início dessa conversa. Naquele momento nós tínhamos uma epidemia de HIV, que significa estigmatização de muitos corpos no interior dos processos sociais, de um modo geral, durante os anos 1980/90. Por outro lado, em 2021 experimentamos um alargamento nas condições de vida por/pelos sujeitos LGBTI+ que me parece um movimento análogo ao pandêmico de COVID-19, e alastramento sindêmico corroborado por discursos governamentais ultraconservadores e fascistas. A tentativa de retorno aos designados LGBTIs, como “portadores do câncer gay”, por conservadores e pessoas ditas de bem enredavam o pânico moral necessário para expurgar-nos das cenas sociais como bodes expiatórios, partícipes desta e outras mazelas, cotidianamente ratificadas como maléficos à sociedade e sem nenhuma estrutura que pudesse nos orientar, a não ser nós mesmas e algum ativismo médico. O mesmo movimento que ocorre com a população mais vulnerável sobretudo de indígenas e pretas no Brasil pandêmico.

\section{3 - E na academia, você se sente incluída? O que falta para a universidade se tornar realmente} um agente de inclusão de todas as pessoas?

É um mundo feito sobre outras lógicas! Eu aprendi a sobreviver na/à rua, com travestis e de modo reativo. A universidade segue sendo excludente, basta perguntarmos a nós mesmas, quantas travestis ou pessoas trans existem nas nossas universidades. As porradas e violência sistêmica no ensino fundamental, hoje é mais elaborada. A sutileza da porrada na universidade é pior, por que ela joga e julga todos como iguais, portadores de voz com potência de escuta e capazes. Os colegas cis-heteros-machos-não deficientes, sequer nos ouvem e quando o fazem agem como sendo algo do campo do alegórico; falam sobre equidade, diversidade e igualdade como se todas as mulheres presentes tivessem a mesma fluidez que seus próprios corpos. $\mathrm{O}$ 
exercício masculinista tóxico coaduna práticas cisheteronormativas de aliança entre os que pactuam com tais ações, conscientemente ou não. Fiz mais de 30 formações durante o ano de 2020/21 apenas sobre uso de banheiros por parte de pessoas trans e travestis. A cada curso, me perguntava: o que estou fazendo aqui? Eu não sou arquiteta ou engenheira! Onde estão estes profissionais, que existem e já recebem por isso, para pensar o banheiro para alunes não binários no espaço acadêmico? Eu sou travesti e posso usar o banheiro feminino ou atender a cisgeneridade que me acusa de "ser homem" e fazer uso do banheiro masculino. A mim não causa estranheza, mas aos meus alunes, alunas e alunos, qual é a indicação dos gestores? Ou seguirão fazendo de conta que tais alunes, alunos e alunas não existem? Este é um caso, mas poderíamos falar de cotas, meu trabalho de mestrado em Educação, que muito mais atende a políticas Púb(1)icas que educacionais. Por ser preteridas, não bastava a crítica social sobre nós, buscávamos defeitos em nós mesmas. Por que o aluno branco, cisgênero e com expressão social supostamente heterossexual, é ouvido e respeitado? Por que minhas dúvidas eram banalizadas e de outra ordem? Tanto na graduação, quanto na Pós, temos relatos do dia do "Meu assunto ou do meu problema”. Discute-se escola púb(l)ica como se fosse um oceano estável e o corpo trans/travesti nela, como exceção. E de tantas exceções, as redes sociais e o ciberespaço nos trouxe corpo(s). O que falta? Eu diria que essa pergunta é no mínimo capciosa, como diria minha avó. Para falarmos de inclusão, primeiramente, eu preciso lembrar que sou uma criança que compreende o mundo muito cedo através da sexualização forçada, como ocorre com todas as crianças. Ninguém aprende sozinho aos 3 anos que calcinha é para meninas e cueca é para meninos. A minha condição de mulher, e não de menina, e depois de travesti, ainda na infância, avilta a conversa se forem ou estiverem fora dos traçados naturalizados(res) da escola. Estou falando de filhos de pai e mãe presentes, de filhos que comemoram datas comerciais nas estruturas seladas pelo patriarcado, como dia dos pais, onde o pai é um homem que tem pênis e a mãe é uma mulher que tem vagina. No meu caso, sou um pai cujo a genitália não corresponde propriamente à avó que represento para o meu neto. Esse é um aspecto recorrente às pessoas trans e travestis, um processo de segregação. Um terceiro, é o processo de integração. Muitas estórias (diferindo de "histórias" que são legitimadas do corpo cis-colonizador) de pessoas trans/travestis narradas em suas redes sociais, sobretudo no Ensino Superior e na Pósgraduação, uma pseudo inclusão dos sujeitos no sistema regular que pretende atender às suas demandas e até corrobora para atividades específicas ou com uma abordagem mais assistencialista ou benevolente. Para falarmos de inclusão precisamos pensar não apenas inclusão, segregação e integração, mas a própria inclusão como um processo que envolve uma 
reforma sistêmica pensando os diversos sujeitos no interior do processo, com modificações reais de conteúdo, estruturas, métodos, metodologias, abordagens e estratégias diferenciadas que visem, de fato, alcançar ao máximo as experiências diferenciadas de alguns sujeitos, contextualizando sua caminhada. A pesquisadora e professora do Programa de Pós-Graduação em Educação da UERJ, Jane Paiva, que trabalha com Educação de Jovens e Adultos, fala de uma inclusão em um processo de exclusão, como uma expressão contraditória e que envolveria a sociedade capitalista como um todo (PAIVA, 2011). Desse modo, pensaríamos pessoas excluídas, marginalizadas, à parte da nossa sociedade. Penso então como pessoas trans e travestis, por exemplo, em uma referência direta dessa exclusão do consumo, de apropriar-se de bens econômicos e daquilo que poderia trazer uma ilusão de inclusão. Assim eu penso sobre os vários processos das alunas travestis, por exemplo numa universidade como a Universidade do Estado do Rio de Janeiro - UERJ, onde no ano de 2021 o professor Doutor em Direito e Magnífico Reitor da Universidade, produz um documento que reitera a Lei Estadual que permite às pessoas trans e travestis o uso do banheiro a partir de suas identidades de gênero. Ao precisarmos de um documento chancelado pela Instituição para gerir o uso de sanitários segundo seus processos anatomo-físiológicos, como urinar e defecar, estamos falando de um corpo que foi incluso? E a quanto tempo? Por outro lado, preciso ressaltar que um movimento democrático, de múltiplos sujeitos, no qual alguns possuem a mesma potência de voz, entretanto diferente potência aos sujeitos de escuta. Essa frase é propositalmente capacitista e age com e segundo os corpos lidos como capazes e onde todos atuam em "pé de igualdade". Com a inserção de professores/as trans/travestis e não bináries, de modo reiterado, nos processos ensino-aprendizagem, sobretudo do Ensino Superior, algumas dessas amarras padronizadas passam a ruir. Como mencionei, o caso das professoras Luma Andrade de Oliveira, Megg Rayara, Letícia Carolina, Adriana Salles, Ana Flor, Maria Clara, Thiffany Odara, Ariadne Ribeiro, Ana Letícia que são alguns dos nomes resistindo e criando possíveis mundos, enquanto travestis, na área da Educação no Brasil. Todas com histórias únicas e que ao mesmo tempo dialogam com lutas coletivas. Estes nomes apontam a possibilidade para mudança nos processos de inclusão de pessoas (trans/travestis, homens trans, pessoas transgêneros, transmasculines) entre tantas outras expressões e identidades, nos espaços acadêmicos. Então, se me perguntam se eu me sinto incluída? Respondo que eu me sinto participante de muitos movimentos de inclusão que atualmente acontecem dentro da Academia. Deste modo, o que seria fundamental à universidade ainda é o processo de sensibilização das narrativas de pessoas excluídas, a compreensão dos processos sistêmicos racistas, misóginos e cissexistas. Que 
despreza ausência de território, mas também a existência de territórios não citados, aqui me refiro a pessoas trans refugiadas e imigrantes e em processos de existência não citada como moradores e moradoras de favelas. É uma constante. Por que apesar de ser "Sara York" e saber me movimentar de alguma forma, tem uma outra menina chegando que ainda sequer definiu seu nome social e tanto a escola, quanto a universidade precisa estar preparada, e não se preparar, para ela. Não temos esse tempo. Incluir significa não apenas corroborar com processo do sujeito, mas um avanço social que retira das margens toda a sociedade.

\section{4 - Qual a importância que você atribui às políticas de ações afirmativas?}

Na minha dissertação de Mestrado pesquisei sobre as muitas faces destas políticas e fui percebendo o quanto andamos em terreno arenoso. Se por um lado é muito óbvio o processo de racialização nacional que adere o sentido de raça a pretos e indígenas, deixando a população branca como não racializada, por outro pergunto-me se travestis (enquanto grupo marginalizado, seguindo os preceitos do racismo), ainda que brancas, seriam do campo do sujeito branco, fluido e alcançável para muitos. Se a travesti é preta, periférica e/ou pobre, ela é uma coitada e digna de ajuda, se for branca e bem-sucedida, ela é alçada ao padrão de exemplo e, em ambos casos, há uma exotificação para uso e sustentação da máquina que reafirma que "enquanto cis" somos melhores, mais capazes e de espírito solidário. O desejo de ser "bom, capaz e aceito" reenquadra até aquelu corpa em abjeção (POCAHY, 2010), mais distante dessa ordem, a praticá-la. Vilma Piedade fala de um conceito chamado dororidade, o sentimento de união entre mulheres negras a partir de vivências similares forjadas pela dor. Assim, para que pareça benevolente quaisquer aspectos de tais ações, as duas faces da mesma moeda, que por um lado pretende promover reparação, por outro ainda é preciso que se diga que os processos de reparação histórica não deveriam passar por movimentos benévolos. Acusações e demérito aos "vitimistas" não é nova, como já citaram a mim, mesmo não sendo cotista no doutorado da UERJ. Eu fui também aprovada na seleção de doutoramento em Educação na UFPR, passando por uma banca de verificação para pessoas trans cotistas, e também no Programa de Psicologia Social da UFRGS, o que reitera o carácter inovador, inclusivo e desafiador de várias professoras em seus Programas e áreas. Entretanto, em alguns momentos ou, como no caso do professor Wallace dos Santos de Moraisi ${ }^{\mathrm{i}}$, acusações por parte daqueles que se sentem amedrontados em seus privilégios também são lançadas. Seguimos dizendo, como tão bem nos ensina Jota Mombaça em seu não manual de ética, "Preciso não escrever sobre como atravessar um 
processo perante o qual me sinto perdida. Preciso não escrever sobre o que fazer quando estou paralisada. Se posso arrancar da paralisia e da confusão um outro modo de escrita" (MOMBAÇA, 2016, p. 1). Não são dois lados da mesma moeda; uma vida trans e uma vida cis são os mesmos lados, uma fita de moebius, cujo o lado de dentro e o de fora são o único lado. Assim, se o racismo é produzido com a presença exagerada do conhecimento do cis-heterobranco, a misoginia e a LGBTIfobia são presenças exageradas de um masculinismo entorpecente no cisheteropatriarcado. Alimentando-se da ausência de uma corpa, obcecado por uma mesmidade, esse masculinismo, que entorpece como uma droga, "odeia a outridade, numa forma feminina da alteridade, e provoca inexistência e ausência dos conhecimentos outros e plurais e, como consequência, admite sua aniquilação como pessoa" (SUSSEKIND; YORK; CARMO, 2020). Esses conhecimentos aniquiladores, abissais, coloniais precisam ser deslocados, descentrados, desconstruídos, nas escolas, num movimento de produção de presença travesti, feminina, negra, pós-binária, múltipla.

5 - A universidade que você cursa o doutorado, a UERJ, foi uma das primeiras a incorporar as políticas de ações afirmativas desenvolvendo cotas para ingresso na instituição para negrxs, indígenas, alunxs oriundxs de escolas públicas, filhxs de policiais e bombeirxs mortxs no exercício da profissão. Assim eu te pergunto: e para as pessoas trans, já existe cotas para vocês na UERJ?

Reparos históricos urgentes! O professor Sérgio Luis Baptista, da UFRJ, questiona com frequência em suas aulas se a cardiopatia, a hipertensão e tantas outras mazelas são eventos naturais em alguns corpos ou se isso estaria longe de um desgaste natural produzido pelo envelhecimento. Há um esteio produzido por esta sociedade sobre alguns corpos, nesse sentido. Quando percebemos que havia uma naturalização do dado de 35 anos como expectativa de vida de pessoas trans/travestis, muitas de nós iniciamos um processo de emergir outras histórias para que, sobretudo, pessoas trans mais jovens não cooptassem a lógica determinista desta informação. Paula Beatriz, mulher trans, preta e responsável a mais de uma década pela gestão da mesma escola na cidade de São Paulo é um exemplo do fazer inclusivo e possível, cujo efeito da diferença (SEPULVEDA \& SEPULVEDA, 2016) nos meandros escolares atende a todas, todos e todes. Mergulhamos na diversidade como sinônimo que alça todos os excluídos e destituídos, mas não é bem assim! A UERJ segue em ampla discussão, principalmente com apoio das docentes pretas da casa, que compreendem o lugar histórico de uma pseudo-inclusão por tanto tempo. Mobilizada num momento em que a noção de humanidade já governava a 
cena ética, o papel principal da racialidade é produzir uma explicação sobre a diversidade humana capaz de negar a possibilidade de que traços mentais (morais e intelectuais), "observados" com o uso do índice facial, mudem com o tempo. Como, de acordo com Hegel e outros, o pós-Iluminismo marcou o momento em que as capacidades mentais europeias atingiram o mais alto grau de desenvolvimento (ao nível jurídico, econômico e moral) possível para seres humanos racionais, a racialidade permitiu, como discutido anteriormente, a demarcação dos limites do 'desenvolvimento', sua circunscrição aos corpos e espaços brancos/europeus, ao produzir o corpo racial como significante das limitações mentais (morais e intelectuais) - que determinam a incapacidade de evoluir e desenvolver dos "outros da Europa" e da unicidade dos brancos/europeus.

6 - Gostaria de te perguntar qual a diferença para as mulheres trans viver no Brasil de Bolsonaro e no Brasil de Lula e Dilma? O que mudou para vocês?

Quando fomos escrever o Manifesto Travesti (2020), encomendado pelas queridas Conceição Soares, Leonardo Peixoto e Larissa Pelúcio, o esqueleto com ideia inicial foi gestado por mim e Rafael Leopoldo, da Filosofia, e ali começava um grande desconforto ao lembrarme da então doutoranda, Megg Rayara, que falava sobre a sua grande responsabilidade para conosco e que era reiterado nas ações da secretária de articulação da ANTRA, Bruna Benevides, em sua pressa para com vários setores que pudessem trazer alguma política que beneficiasse as tantas travestis pelo Brasil. Juntas adicionávamos muitas ideias e Bruna, especialmente, foi quem trouxe uma que foi muito profunda e que mexe com várias de nossas cicatrizes, ela disse, "Sobrevivemos à epidemia do HIV. Somos filhas da AIDS. Netas da Violência. E hoje queremos mais (em terra Brazilis, quem perdoa é Jesus!), queremos reparação histórica, já!” (YORK; OLIVEIRA; BENEVIDES, 2020). Estávamos falando do fruto que amarga em nossas bocas, seja pela contaminação com HIV de muitas das nossas, seja com a perda de muitas de nossas ancestrais para a AIDS, com um empurrão generoso por parte do Estado. Acredito que os anos 1980 tenham sido os anos mais dolorosos que nossa comunidade vivenciou como um todo. Eram muitas mortes e a indicação de contaminação era o prelúdio para morte e, assim, eu particularmente assisti a morte de quase todas as minhas amigas travestis naquela década. Havia um movimento de ausências por parte do Estado durante a Ditadura Militar, o terror e lembranças daquele período, giravam em minha mente. Da primeira ferida na pele ocasionada pelo sarcoma de Capossi à segregação para morte. O governo Militar não apresentou, por 
muitos anos, nenhuma política de assistência aos contaminados e rejeitava discussão, inclusive produzindo pânico moral com o famoso bode expiatória do câncer gay. Eu vi, eu estava lá! E ainda não consigo explicar e/ou ressignificar o que senti, vivi e vi. O apelo à educação e às artes fazem dos anos 2000, principalmente a partir da segunda metade do primeiro século, algum alento. 2004 foi o ano que o governo instituiu o Programa FIES, responsável de forma direta pelas medidas de democratização do acesso ao Ensino Superior, política fortemente defendida pelo governo Lula. Já em 2005 temos a criação da UAB, que consideramos o "divisor de águas" (VIEIRA; SILVA; VIEIRA, 2017; YORK, 2020). O EAD passa a ser uma realidade que possibilita o acesso à Educação em Nível Superior, apesar de ainda, naquele momento, não haver propriamente um gerador de inserção educacional. Como disse, Frantz Fanon (1961), “a colonização é maniqueísta e somente a descolonização é heterogênea”. Era o início de novos rumos. O governo Bolsonaro marca nossas vidas não por uma batalha para com um vírus e uma pandemia, não pela falta de promoção social e pela vida, mas por sua gestão amparada na carnificina, no ódio e na habilidade de promover guerras naquilo que ele diz defender: as famílias. O estímulo à guerra nos núcleos familiares sob constante produção e manipulação de mentiras fez com que pessoas em um mesmo grupo de afetos e amorosidades passassem a se estranhar e se odiarii ${ }^{\text {ii }}$ Bolsonaro usou de técnicas de ódio para fomentar o que de pior havia em nossas casas e que há muito tentávamos discutir, melhorar e evoluir: a falta de respeito e empatia com as/os nossas/os. Eu jamais havia experimentado a violência direta contra minha pessoa, enquanto docente, por parte de alunas e alunos até aquele momento. Em 2018, tive não apenas dezenas de embates no interior das escolas onde trabalhava, principalmente incentivados por brincadeiras de professores/as abertamente bolsonaristas que, tardiamente, me enviariam mensagens com pedidos de desculpa.

Figura 1 - Um dos bilhetes que eram deixados por uma colega em meu material na sala dos professores/as diz, "Oi, 17 beijos para você" com sua assinatura que alude a uma face pueril que contrastava com o número da legenda do Partido Social Liberal - PSL, do então candidato presidencial. O 17 de Jair Bolsonaro, que mesmo fazendo "arminha com as mãos" e era inserido de modo lúdico entre às crianças, por aqueles/as que defendiam uma "escola sem partido". 


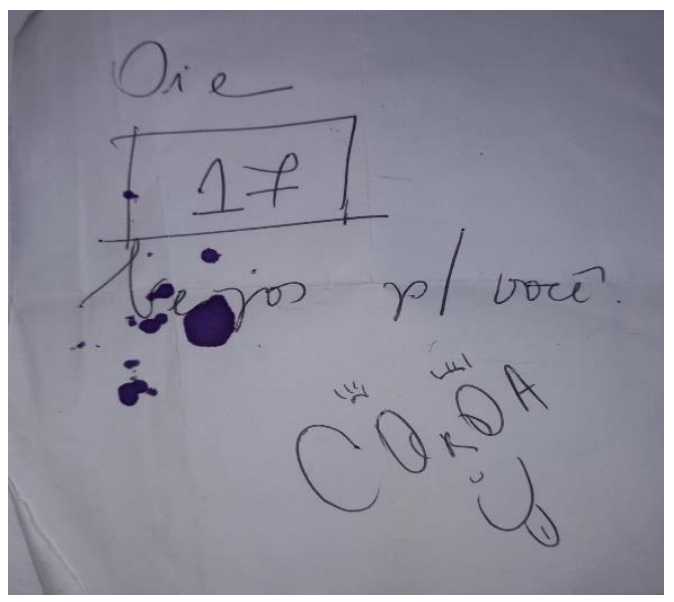

7 - Sabemos que durante a Ditadura civil militar existia uma política oficial de morte direcionada às pessoas trans. E no momento atual, podemos dizer que essa política continua ocorrendo? O que mudou de lá para cá?

Ceu Cavalcanti ( et all), mulher trans, nordestina e vice-presidente do Conselho Regional de Psicologia, escreve sobre esse momento de modo sensível em um texto nomeado "Os tentáculos da tarântula”, fazendo alusão à genitália da fêmea estereotipada como aranha, assim, a vagina, e não a vulva, faz relação anacrônica nociva e perigosa dessa "aranha" de outra ordem. O texto questiona esse status que lança o cliente como um enganado pela ilusão cruel ofertada pelo sujeito "travestido". Uma de nossas repulsas a flexão da palavra travesti, inclusive, gira em torno do modo folclórico, piadístico e sempre pejorativo aplicado em muitos discursos. Este texto questiona enredos dados e recupera a memória travesti que a sociedade tenta esquecer e colocar de lado. Em 2020, a pedido da Fundação Rosa Luxemburgo, eu e Neon Cunha - uma liderança cujo trabalho antecede sua deliberada militância, ao ser levada a pedir morte assistida pela falta de garantia de vida digna, enquanto cidadã no Brasil - escrevemos que a partir de nossas lembranças, em diálogo com textos como de Céu Cavalcanti, no Brasil, os policiais faziam rondas sistemáticas para ameaçar e prender mulheres trans, travestis, gays e lésbicas, chegando a prender 1,5 mil pessoas apenas na cidade de São Paulo durante as décadas de 1970 e 1980. Havia assim, neste período, os sempre defensores da moral e dos bons costumes, como evidencia, inclusive, o trabalho de Renan Quinalha, lançado em 2021, de mesmo nome, a partir de sua tese de doutorado. Os militares viam as LGBTQI+ como particularmente indesejáveis. O grau dessa perseguição, levando em conta o preconceito e a discriminação em dimensão institucionalizada, mostra a omissão do Estado para com tais vidas. Operações policiais eram frequentes em todo país no final dos anos 1970; a primeira, em 1968, acontece em decorrência da visita da Rainha Elizabeth II à cidade de São Paulo - SP. 
Algumas coisas mudaram o mundo e o mundo precisou se atualizar de suas políticas amparadas pela morte e ausências. Travestis seguem as políticas de sobrevivência com prostituição compulsória; temos dados dessa adequação. A tentativa de aderir à cisgeneridade, como tática de sobrevivência, também segue os aspectos daquele momento que alocava algumas travestis às condições de "parece mulher mesmo", enquanto aquelas com "cara, voz e jeito" de travesti seguem ainda na ordem da inclusão benevolente. Bruna Benevides sempre lembra em suas diversas falas que se uma pessoa trans/travestis entrou em um espaço e ninguém a viu, nenhuma pessoa trans/travesti ali entrou. O que converge à naturalização de nossas percepções nos muitos espaços, tornando comum algumas presenças e outras nem tanto.

\section{8 - Você tem uma utopia de vida? Se sim qual?}

Utopia me remete a aspectos mais sociológicos do que históricos! Paul Preciado, em seu texto pós COVID19 ${ }^{\text {iii }}$, nos informa que a primeira ação foi escrever uma carta de amor. Escrever cartas e manifestos é uma estratégia da fantasia colonial, mas neste tempo, reaparece como um arcabouço disruptivo. Talvez por perceber a fragilidade da vida, para algumas de nós, pessoas trans, se jogar para o tudo ou nada já se fazia recorrente, como amplamente dito por Katia Tapeti, Jovana Cardoso, Keila Simpson entre tantas outras. A gestão política das epidemias (como sífilis, HIV ou dengue, por exemplo) já vinha nos lançando ao absurdo que chegamos ao pensarmo-nos como habilidosos sujeitos, capazes de lidar com a morte do Outro, curar-se das doenças e mantermo-nos imunes comemorando a vida. Não consigo pensar de modo tão confortável ao perceber que, em cena, há uma utopia coletiva com sonhos de imunidade e uma reafirmação dos vitoriosos. O sujeito neoliberal, apto e, repito, capaz, mais do que nunca se apresenta como grande promessa de um futuro. Ele é LGBTI, reconhece seus privilégios, tem alguma deficiência que possa acionar, mas se apresenta como empreendedor e sábio em várias frentes, enquanto seus pares menos (d)eficientes se degladiam por um minuto de fama no TikTok. A utopia flerta com a soberania política, com o sujeito onisciente cujo relações líquidas tornam-no mestre de sua própria Caixa de Pandora, de seu Cavalo de Troia ou de sua Garrafa de Klein. Surpresas não previstas, invasões (auto)destrutivas e (in)findáveis argumentações. Tenho chamado a atenção a algum tempo sobre a produção de arquivo, preservação de memória e observância dos fatos que nos atravessam neste momento, os "arquivos são um ou vários produtos de um processo que converte um determinado número de documentos em itens julgados dignos de preservação e conservação" (MBEMBE, 2002). A história (auto)biográfica, a (auto)etnografia, as (auto)narrativas de si tem produzido formas que revisam nossa história, 
atualizando sua consistência democrática. A simples ideia de uma democracia já pode estruturar muitas de nossas escolhas e caminhos. A democracia não vivenciada de quase 600 mil mortos nos expõe a sua irrealizabilidade, mas sugere o que ainda temos. Alternativas básicas que podem propiciar algum conforto foram sugeridas por instâncias do judiciário no Brasil. Um levantamento produzido pelo Instituto de Pesquisa Econômica Aplicada (Ipea) e o Fórum Brasileiro de Segurança Pública (FBSP) apresentou o Atlas da Violência 2021 iv e nele "o campo sexo possui as alternativas masculino, feminino e ignorado, sendo separado do campo identidade de gênero. O campo identidade de gênero conta com as alternativas travesti, transexual mulher, transexual homem, não se aplica e ignorado. Isso faz com que pessoas Intersexo estejam forçadas a uma declaração invisibilizante de sua especificidade. Assim, 98,8\% dos registros não possuem a informação sobre identidade de gênero, porque a metodologia é incapaz de conceber cisgeneridade enquanto identidade de gênero" (ATLAS da violência, 2021). A cisgeneridade não se complexifica, assim como a branquitude! Uma das perguntas que me faço com muita frequência é sobre as práticas autorizadas no discurso de quem fala no contexto escolar. Explico: um colega do Curso de doutoramento em Matemática apresentou um trabalho onde ele colocava no quadro algumas palavras obscenas ou palavrões proferidos pelos alunos de sua sala de aula e, a partir daqueles palavrões, eram discutidos vários conceitos matemáticos. Por exemplo, quantos por cento dos alunos utilizam tal "palavrão" como forma de xingamento? E a expressão numérica era desenvolvida a partir daquela questão. Ao pensar a mesma dinâmica em uma sala de aula regida por mim, enquanto professora de língua estrangeira da disciplina de inglês ou de língua portuguesa, posso eu utilizar os mesmos termos ou metodologia para disparar a discussão a respeito de vários modos constitutivo da língua? Em minhas aulas e palestras costumo questionar padrões, esses gêneros cisheterocentrados e formas compulsórias naturalizadas nos múltiplos espaços, faço isso com vastos moldes exemplificados do meu cotidiano, mas, ainda assim, sempre recebo um exemplo genérico que a mim não se aplica. Isso significa que não basta dizer "precisamos quebrar os padrões cis-hétero excludentes", é preciso que a pessoa que o diga seja parte tocada neste espaço. Ao termos um professor retirado de sua sala, exonerado de seu cargo na cidade de Criciúma, a defesa não deveria ser legitimada pelo discurso de um outro professor, cis-héterobranco-saudável-seminal e autorizado, mas justamente pelos sujeitos que entram em demérito segundo aquele discurso. Precisamos escutar as primeiras máquinas da Revolução Industrial, as máquinas vivas, que seguem inaudíveis nas telas diversas de nosso conforto.

\section{9 - Há alguma outra consideração que você gostaria de trazer?}


O número 8 nos remete ao símbolo do infinito, assim, reiterando que essa discussão não se encerra aqui, quero trazer algumas considerações. É urgente que criemos laços fora da lógica cisheteronormativa de produção que ignora outros saberes e formas de produção. Existem grupos que ainda lutam por vocabulário para expressar sua condição no mundo (dos vencedores), em alusão aos fracassados de Jack Halberstan. Algumas palavras trarão acuidade para aquilo que é dito por alguns cânones, mas não farão sentido para um corpo que foi remetido a noção de contraproducente ao longo de sua vida. O Bájuba e o Pájuba, por exemplo, são produções de e para os corpos para escapar da perseguição branca-cis-heteronormatizadora ao longo da vida. Quando dizíamos “desaquenda, ó u alibã”, era uma forma de anunciar as parceiras que a polícia, paga para prover segurança a todos, lá estava para produzir marginalidade e violência. Tinha gozo e prazer, para ambos os lados, mas a custo de muita dor e muitas perdas para o nosso. Alguns aspectos mudaram. Nos últimos cinco anos não tivemos registros de violência seguida de morte produzida diretamente por policiais (civis e militares) em serviço, como nos anos de perseguição em prol da família, da moral e dos bons costumes. Até a perseguição evoluiu, este ano por exemplo, a Escola Municipal de Ensino Fundamental Conde Pereira Carneiro foi perseguida por legisladores fundamentalistas e pseudoconservadores. Ao grafitar seus muros com palavras e imagens de apoio as comunidades historicamente marginalizadas, a escola lança mão do modo mais básico de linguagem para ensinar sobre/com inclusão, respeito e cuidado. Segundo o Instituto Brasileiro de Geografia e Estatísticas - IBGE (2020) no Brasil há mais de 17 milhões de pessoas com algum tipo de deficiência; segundo Associação de Pessoas Intersexo - ABRAI, em 2020 foram notificados 28 mil bebês com sexo ignorado (são bebês Intersexo e estão numa margem dos 1,7\% da população mundial de nascidos sob outras condições ainda precariamente apresentadas em números no Brasil). Em 2021, produzimos um dossiê com corpes outres, justamente pela falta de um aprofundamento sobre gênero, sexualidade e deficiência produzido por corpos trans e travestis com deficiência. Lembro-me da produção do Dossie (Trans)insurgências, cujo a capa é de Luiza Lemos e Laerte Coutinho. O dossiê foi produzido pela RE-DOC com apoio de Edmea Santos e Felipe Carvalho, nele, grandezas como Renata Carvalho, Sofia Favero e Jaqueline Gomes de Jesus apresentam trabalhos atendendo ao convite de uma travestimestranda, foi ousado! Estar junto na possibilidade da falha é um marco que apenas quem se arrisca, pode alçar vitória. Outro dado recorrente é que nos últimos 13 anos de estudos apresentados pelo GGB e ANTRA, são os números das mortes de pessoas trans/travests, que aloca o Brasil à triste posição de país que não apenas persegue (uma vez que é o país que mais 
consume pornografia LGBT do mundo) como também o que mais mata. No Relatório da ANTRA (2021) apresentamos uma secção que denuncia as práticas de alguns conservadores e religiosos fundamentalistas que propagam ódio contra pessoas trans e travestis no ciberespaço. A nossa dívida ou a da cisgeneridade conosco é impagável (DA SILVA, 2019), por isso o grito à repação histórica urgente. $\mathrm{O}$ grito mencionado, é uma metáfora há quem diga que está nos dando voz! A voz que sempre tive(mos). Eles não apenas invisibilizam as condições de pessoas com deficiência no Brasil, mas tratam a comunidade surda (de minoria linguística no Brasil) como inexistentes e usando a palavra diversidade de modo conveniente para seus intentos, não especificando se a tal diversidade é por exemplo, sobre crianças com síndrome de Down, lésbicas cristãs, travestis negras ou adolescentes autistas. Tudo que não tem atenção por parte destes grupos ditos conversadores são colocados em uma palavra que pouco explica suas intenções e com quais funcionalidades. Dados não nos faltam para o confronto à forma falaciosa e rasa que parte de alguns membros do legislativo de viés conservador e as perseguições rotineiras, seja em Minas Gerais (com Duda Salabert e sua sabedoria diante do dedo em riste do vereador cristão que lhe acusava), Rio de Janeiro (Taliria Petrone, Benny Briolly e como não lembrar de Marielle Franco?), em São Paulo (Erika Hilton, Erica Malunguinho, Carolina Iara, travesti e Intersexo, que teve sua casa alvejada por tiros) e/ou em tantos outros Brasis. O Brasil pandêmico, marcado pelo luto, pela ausência dos que se foram e pela luta pela sobrevivência, tem se refeito pelo trabalho não mais hercúleo, mas diânico pelas mãos daquelas que nele acreditam. Como trago vários nomes trans/travestis como referência nos meus trabalhos e falas, sendo propositiva, quero também agradecer as grandes cis-aliadas que tem possibilitado alguma visibilidade sobre meus trabalhos, citando diretamente minha orientadora e parceira de caminhada, a Professora Doutora Denize Sepulveda e a todas as "esperancistentes" v professoras da Faculdade de Formação de Professoras/es (FFP) da Universidade do Estado do Rio de Janeiro e de outras programas que acesso.

\section{Referências}

ARENDT, Hannah. Entre o passado e o futuro. Trad. Mauro W. Barbosa. São Paulo: Perspectiva, 2011.

BRASIL. Constituição da República Federativa do Brasil. Brasília: Diário Oficial, 5 out. 1988. Disponível em: <http://www. planalto.gov.br/ccivil_03/constituicao/constituicao.htm>. Acesso em: 29 ag. 2021. 
CARA, Daniel Trajeiro. Entrevista Sara York: A Travesti da/na educação. Entrevista sobre atuação e vida da professora Sara Wagner York. Educação. UFSM, v. 45, p. 110-1-35, 2020.

CAVALCANTI, Céu, et all. The Tarantula Tentacles: Abjection and Necropolitics in Police Operations to Trans Women in Post-redemocratized Brazil. Psicologia: Ciencia e Profissão, v. 38, n. número especial 2, 2018.

DOSSIÊ dos assassinatos e da violência contra travestis e transexuais brasileiras em 2020. Bruna G. Benevides, Sayonara Naider Bonfim Nogueira (Orgs). São Paulo: Expressão Popular, ANTRA, IBTE, 2021

DOUGLASS, Frederic. Frederic Douglass: Autobiografia de um escravo. São Paulo: Editora vestígio. 2021.

FANON, Frantz. Os condenados da terra. Rio de Janeiro: Editora Civilização Brasileira, 1961

MBEMBE, Achille. "The Power of the Archive and its Limits." Refiguring the archive. Springer, Dordrecht, 2002. 19-27.

MOMBAÇA, Jota. O mundo é meu trauma. PISEAGRAMA, Belo Horizonte, número 11, página $20-25,2017$

OLIVEIRA, Megg Rayara Gomes de. O diabo em forma de gente: (r)existências de gays afeminados, viados e bichas pretas na educação. 2017. 190 f. Tese (Doutorado em Educação) - Programa de Pós-Graduação em Educação, Universidade Federal do Paraná, Curitiba, 2017.

PAIVA, Jane. Inclusão na Educação de Jovens e Adultos. Revista Eletrônica Debates em Educação Científica e Tecnológica - ISSN: 2236-2150, [S.1.], v. 1, n. 01, abr. 2011. ISSN 2236-2150. Disponível em: 〈https://ojs2.ifes.edu.br/index.php/dect/article/view/3/2>. Acesso em: 01 set. 2021.

PRECIADO, Paul. B. Um apartamento em Urano: Crônicas da travessia. Prefácio de Virginie Despentes. Zahar. 2020.

POCAHY, Fernando. Um corpo entre o gênero e a sexualidade: notas sobre educação e abjeção. Instrumento: Revista de Estudo e Pesquisa em Educação, Juiz de Fora, v. 12, n. 2, p. 125-135, 2010.

SEPULVEDA, José Antonio; SEPULVEDA, Denize. As práticas e as políticas curriculares de inclusão e o direito à diferença. Revista e-Curriculum, v. 14, n. 4, p. 1258-1287, 2016.

SILVA, Denise Ferreira da. A dívida impagável. Trad. Amilcar Packer e Pedro Daher. São Paulo: Forma Certa, 2019.

VIEIRA, José Jairo; SILVA, Priscila Aleixo da; VIEIRA, Andréa Lopes da Costa. A Política de educação a distância e o aumento das vagas nas instituições de ensino superior: apontamentos. Revista on-line de Política e Gestão Educacional, p. 776-792, 2017. 
YORK, Sara Wagner. Tia, você é homem? Trans da/na educação: Des(a)fiando e ocupando os "cistemas" de Pós-Graduação. 2020. 190 p. Dissertação (Mestrado em Educação) orientada pelo professor Doutor Fernando Altay Pocahy com bolsa CNPq - Faculdade de Educação, Universidade do Estado do Rio de Janeiro, Rio de Janeiro, 2020.

. Apresentação do dossiê CRIP. Educação em Análise, v. 6, n. 1, p. 3-8. 2021. Disponível em: 〈http://www.uel.br/revistas/uel/index.php/educanalise/issue/view/1774/showToc $>$.

Acesso em: 18 set. 2021

YORK, Sara Wagner; OLIVEIRA, Megg Rayara Gomes; BENEVIDES, Bruna. "Travesti Textual (insubmiss) Manifestations". Revista Estudos Feministas 28.3 (2020).

i Disponível em: <https://odia.ig.com.br/rio-de-janeiro/2021/08/6221763-professor-da-ufrj-denunciadiscriminacao-de-cunho-racista-na-universidade.html >. Acesso em: 20 set. 2021.

i Em outro momento, tive meu carro vandalizado e sem nenhum apoio ou registro por parte da direção da escola. Não gostaria que minhas alunas e alunos fossem criminalizados, sendo principalmente em sua maioria pessoas em situação de grande vulnerabilidade, mas esperava que a direção da escola e secretaria municipal de Educação de São Pedro da Aldeia tivessem uma postura minimamente pedagógica e educativa, discutindo tais questões naquele espaço. Disponível em: $<$ https://prensadebabel.com.br/ativista-trans-tem-carro-vandalizado-por-fascistas-em-saopedro-da-aldeia/>. Acesso em: 19 set. 2021.

iii Disponível em: https://sarawagneryork.medium.com/a-conspira\%C3\%A7\%C3\%A3o-dos-perdedoresbabd1f6b4c10>. Acesso em: 17 set. 2021.

iv Disponível em: <https://www.ipea.gov.br/atlasviolencia/arquivos/artigos/1375atlasdaviolencia2021 completo.pdf >. Acesso em: 17 set. 2021.

${ }^{v}$ Atributo de quem semeia insistentemente a esperança entre as/os suas/seus, marcando um tempo que nossos laços eram alimentados no ciberespaço ante o distanciamento geo-social que nos preservaria do novo vírus, mas não das antigas mazelas do isolamento, que pessoas trans/travestis. É preciso dizer que durante as aulas do Doutoramento em Educação, em todo segundo semestre de 2020 e ano de 2021, a emoção, a dor, os afetos, as perdas e as lágrimas se faziam constantes em todas as aulas que me formavam, informavam, deformavam, reformavam, renovavam e além, me inspiravam a seguir sorrindo com Marcia Alvarenga, Sonia Câmara, Rosimere Dias, Maria Rita Cesar, Megg Rayara de Oliveira, Paula Sandrine Machado, Rosa Malena, Ana Chrystina Mignot, Edmea Santos, Maria Luiza Sussekind, Vanessa Leite, Inês Barbosa, Fatima Lima, Maria Elvira Benitez e Camila Fernandes. 